\title{
Determining of Health Literacy Level in Elderly: An Example of Eastern Turkey
}

\author{
Hasret Yalcinoz Baysal ${ }^{1(\underline{D})}$ Metin Yildiz $^{2(\underline{D})}$ \\ ${ }^{1}$ Department of Public Health Nursing, Faculty of Nursing, Ataturk Universty Erzurum, Turkey, \\ ${ }^{2}$ School of Health, Ibrahim Cecen University, Agri, Turkey,
}

Copyright@ Author(s) - Available online at https://dergipark.org.tr/en/pub/mbsjohs

Content of this journal is licensed under a Creative Commons Attribution-NonCommercial 4.0 International

License,

Received: 08 September 2020, Accepted: 23 February 2021, Published online: 30 April 2021

(C) Ordu University Institute of Health Sciences, Turkey, 2021

\begin{abstract}
Objective: Knowing the health literacy levels of the elderly is important for better health care. The aim of this study was to determine health literacy level of the elderly.

Methods: This descriptive cross-sectional study was conducted between April 2018 and November 2018. The study population comprised individuals aged over 65 years living in the eastern province, who applied to Family Health Centers for any reason between April 2018 and November 2018 and accepted to participate in the study (983 individuals). Personal information form and Health Literacy Scale were used to collect data Institutional and ethical approvals for the study were obtained. The number, percentage, mean, parametric and nonparametric tests and Pearson correlation test were used to evaluate the data.

Results: The mean Health Literacy Scale total score of the participants was $44.00 \pm 9.10$. A statistically significant difference was found between the mean Health Literacy Scale total score of participants and the marital status, social security, chronic disease status, type of chronic disease and regular drug use. A weak negative correlation was found between the mean Health Literacy Scale scores of the elderly and age.

Conclusion: As a result of our research, the health literacy level of the elderly is moderate and needs to be improved further. To increase the health literacy level of the elderly, local governments, health institutions and health workers should take the necessary measures.
\end{abstract}

Key words: Elderly, Health Literacy, Health Promotion, Turkey.

Suggested Citation: Yalcinoz Baysal H, Yildiz M. Determining of health literacy level in elderly: an example of eastern Turkey. Mid Blac Sea Journal of Health Sci, 2021;7(1):7-14.

\section{Address for correspondence/reprints:}

Hasret Yalcinoz Baysal:

Telephone number: $+90(442) 2313021$

E-mail: h.yalcinoz@hotmail.com

\section{Introduction}

Health literacy defined as "the ability of the individual to reach, understand and use health information for the preservation and maintenance of health" (1). For the elderly, Health literacy is a replaceable factor affecting self-management and health outcomes (2). With the rapid increase in the ratio of the elderly population among the dependent population in recent years, improving the health of the elderly, increasing the level of welfare and reducing health inequalities have gained importance in terms of elderly welfare. According to the projections of the United Nations, the ratio of the elderly population is estimated to reach $21 \%$ of the world population by 
2050 (3). According to the Turkey Statistical Institute data, elderly population in Turkey is approximately 6 million and constitutes $7.7 \%$ of the total population (4). It is estimated that this ratio will reach $20.8 \%$ in 2050.

This rapid progress of the elderly population in aggregate increases the importance of health literacy for the elderly and social welfare (1). It is proposed that the level of health literacy among the elderly is lower than that among individuals in other age groups, especially because of the increase in chronic diseases, decline of cognitive and physical abilities and reduced social and economic support $(1,2)$. Thus, it can be argued that ageing is one of the major factors affecting health literacy $(4,5)$. It was reported in a study that individuals over 65 years constituted the most risky groups in terms of low health literacy level (1). In other words, the level of health literacy decreases with ageing $(1,5)$. In the study by Bozkurt and Demirci in Turkey, it was found that $85.1 \%$ of elderly individuals over 65 years had inadequate or problematic health literacy levels (6). In a study conducted in the America, a one-point decrease in functional health literacy level was observed for each year of increasing age (7).

It is noted that chronic diseases are more common in the elderly population, and these chronic diseases are concomitant with other diseases. It is emphasized that health literacy rate is low among individuals over 60 years of age, and elderly individuals have problems filling forms in hospitals and answering questions. It is also reported that individuals in this age group occasionally fail to ask important questions regarding their health (5-7). In a study conducted by Von Wagner et al. on individuals aged 18-90 years, it was found that health literacy levels of the elderly, undereducated, male and low-income individuals were low (8).

Nurses can support increased health literacy by using similar examples based on previous life experiences of the elderly (9). Nurses' relationship with the elderly evolves over time, individuals may be willing to ask what feeling the lack of health literacy more comfortable express or understand and understand the health information provided by the clinician (10).

In this context, in elderly individuals, who are considered to constitute a fragile group in terms of life period, accessing accurate health information, being able to comment this knowledge and apply it in their everyday lives and being able to receive the necessary services, that is, being health literate individuals, are important in terms of elderly health and quality of life. However, this situation should be evaluated in terms of its contribution to active ageing $(1,3)$. As noted by the World Health Organization, active ageing is associated with the elderly people's ability to benefit from opportunities such as health, safety, and participation in society at an adequate level in order to increase the quality of life $(2,4)$. From this point of view, the purpose of this study was to determine the health literacy level of the elderly and factors affecting it and discuss these factors in light of the literature.

\section{Methods}

\section{Study Design}

This study was designed as a descriptive crosssectional study. The study was carried out at Family Health Centers located in the eastern province center between April 2018 and November 2018.

Study population consisted of individuals aged over 65 years. The sample of study consisted of 983 individuals who consulted to Family Health Centers in the eastern province for any reason and accepted to participate in the study.

After explaining the purpose of the research by the researcher to the individuals who applied to Family Health Centers for any reason between April 2018 and November 2018. Following that, the questionnaires were applied based on voluntariness, and the data were collected (10-15 $\mathrm{min}$ in average).

Personal information form and Health Literacy Scale (HLS) were used to collect data.

1. Personal Information Form: This form is prepared by the researcher in accordance with the literature and consists of 10 questions related to personal and professional characteristics.

2. The 14-item Health Literacy Scale (HLS-14): HLS was developed by Suka et al. in Japan to measure the health literacy level of adults (11). The Cronbach alpha value of the scale was found to be 0.81 . Consisting of 14 items, the scale has the following three sub-dimensions: functional health literacy, interactive health literacy and critical health literacy. The validity and reliability study of the Turkish version was performed by Turkoglu and Kilic and the Cronbach alpha value was found to be 0.85 (12). In our study, the Cronbach alpha value was 0.88 . 'Functional health literacy sub-dimension': It demonstrates the basic literacy skills of individuals. This sub-dimension comprises five items, which are associated with health risks or how to use the health system and the ability to read basic health education materials (reading prescriptions, reading prospectuses and reading and understanding the 
information necessary for care). These are items 1,2 , 3, 4 and 5. The Cronbach alpha value of this subdimension was found to be 0.83 , whereas it was 0.89 in our study.

'Interactive health literacy sub-dimension': It includes advanced cognitive, literacy and social skills. This sub-dimension is defined as the patient exhibiting independent behavior, being able to make decisions about their own health status and communicating effectively with healthcare professionals. This sub-dimension consists of five items (items 6, 7, 8, 9 and 10). The Cronbach alpha value of this sub-dimension was found to be 0.85 , whereas it was 0.80 in our study.

'Critical health literacy sub-dimension': This subdimension, which covers advanced cognitive and social skills to be used in the critical analysis of health-related information and making health decisions, consists of four items. These are items 11, 12, 13 and 14. The Cronbach alpha value of this subdimension was found to be 0.76 , whereas it was 0.80 in our study.

The scale items are scored between 1 and 5 points. Each item of the scale is graded as a 5-point Likerttype item between 'strongly disagree' ( 1 point) and 'strongly agree' (5 points). The total score that can be obtained from the scale ranges between 14 and 70 points. Higher scores indicate a higher health literacy level

\section{Statistical analysis}

The analysis of the data was done on the computer using the Statistical Package for the Social Sciences (SPSS-22) statistical software. Frequency, descriptive, percentage, mean, standard deviation, explore and normality plots with tests were used as descriptive statistical methods. Kolmogorov Smirnov test was used to test normality distribution with analytical tests. Mann-Whitney U test was used for data that is not normally distributed for binary groups. Kruskal-Wallis test was used for data that is not normally distributed for groups more than two. Spearman correlation test was used to determine whether there is a linear relationship between the two numerical measurements, the direction and severity of this relationship, if any. In our study ( $p<0.05$ ), it was accepted as statistically significant difference.

\section{Results}

The mean age of the participants was $73.74 \pm 6.66$ years. Of the participants, $61.7 \%$ were women, $52.7 \%$ were married, $64.2 \%$ were primary school graduates,
$81.8 \%$ were insured, $47.1 \%$ had income equal to their expenses and $90.6 \%$ had chronic diseases. $20.7 \%$ of the participants had diabetes, $28.2 \%$ had hypertension, $12.2 \%$ cholesterol, $14.0 \%$ osteoporosis, and $15.6 \%$ other diseases. Of the elderly, $81.3 \%$ had family history of chronic disease, and $89.3 \%$ regularly used medication (Table 1).

As shown in Table 2, no statistically significant difference was found between the HLS mean scores of participants based on gender, income status and family history of chronic diseases $(p>0.05)$. Based on the marital status, the difference between the HLS mean scores of elderly individuals was statistically significant $(\mathrm{p}<0.05)$. Single individuals had a higher mean score than married individuals. Based on the educational status, the difference between the HLS mean scores of elderly individuals was statistically significant $(p<0.05)$. University graduates had a higher mean score. Based on social security, the difference between the HLS mean scores of elderly individuals was statistically significant $(\mathrm{p}<0.05)$. Individuals with social security had a higher mean score. Based on the chronic disease status, the difference between the HLS mean scores of elderly individuals was statistically significant $(p<0.05)$. Individuals with a chronic disease had a higher mean score. Based on the type of chronic disease, the difference between the HLS mean scores of elderly individuals was statistically significant $(\mathrm{p}<0.05)$. In the post hoc (Dunn) analysis, the difference was found to be caused by osteoporosis and hypertension. The HLS score mean of individuals with hypertension was found to be higher.

Based on regular drug use, the difference between the HLS mean scores of elderly individuals was statistically significant $(p<0.05)$. Individuals with regular drug use had a higher mean score.

As shown in Table 3, the functional health literacy sub-dimension mean score of the participants was $15.616 \pm 4.72$, interactive health literacy subdimension mean score was $15.866 \pm 3.70$, critical health literacy sub-dimension mean score was 12.829 \pm 3.11 and the mean total score was $44.00 \pm 9.10$. As shown in Table 4, there was a statistically significant and weak negative correlation between the mean HLS total score and age of elderly people $(\mathrm{p}<0.05)$. 
Table 1. Demographic characteristics of the elderly (N=983)

\begin{tabular}{|c|c|c|c|}
\hline Variables & & $\mathbf{n}$ & $\%$ \\
\hline Gender & $\begin{array}{l}\text { Male } \\
\text { Female }\end{array}$ & $\begin{array}{l}376 \\
607\end{array}$ & $\begin{array}{l}38.3 \\
61.7\end{array}$ \\
\hline Marital Status & $\begin{array}{l}\text { Married } \\
\text { Single }\end{array}$ & $\begin{array}{l}518 \\
465\end{array}$ & $\begin{array}{l}52.7 \\
47.3\end{array}$ \\
\hline & Primary school graduate & 631 & 64.2 \\
\hline Educational Status & $\begin{array}{l}\text { Secondary school graduate } \\
\text { High school graduate } \\
\text { University graduate }\end{array}$ & $\begin{array}{c}224 \\
120 \\
8\end{array}$ & $\begin{array}{c}22.8 \\
12.2 \\
0.8\end{array}$ \\
\hline Social Security & $\begin{array}{l}\text { Yes } \\
\text { No }\end{array}$ & $\begin{array}{l}804 \\
179\end{array}$ & $\begin{array}{l}81.8 \\
18.2\end{array}$ \\
\hline Levels of income & $\begin{array}{l}\text { Less income than expenditure } \\
\text { Equal income and expenditure } \\
\text { More income than expenditure }\end{array}$ & $\begin{array}{c}431 \\
463 \\
89\end{array}$ & $\begin{array}{c}43.8 \\
47.1 \\
9.1\end{array}$ \\
\hline Chronic Disease Status & $\begin{array}{l}\text { Yes } \\
\text { No }\end{array}$ & $\begin{array}{c}891 \\
92\end{array}$ & $\begin{array}{c}90.6 \\
9.4\end{array}$ \\
\hline Type of Chronic Disease & $\begin{array}{l}\text { Diabetes } \\
\text { Hypertension } \\
\text { Cholesterol } \\
\text { Osteoporosis } \\
\text { Other }\end{array}$ & $\begin{array}{l}203 \\
277 \\
120 \\
138 \\
153\end{array}$ & $\begin{array}{l}20.7 \\
28.2 \\
12.2 \\
14.0 \\
15.6\end{array}$ \\
\hline Chronic Disease Status in Family & $\begin{array}{l}\text { Yes } \\
\text { No }\end{array}$ & $\begin{array}{l}799 \\
184\end{array}$ & $\begin{array}{l}81.3 \\
18.7\end{array}$ \\
\hline Regular Drug Use Status & $\begin{array}{l}\text { Yes } \\
\text { No }\end{array}$ & $\begin{array}{l}878 \\
105\end{array}$ & $\begin{array}{l}89.3 \\
10.7\end{array}$ \\
\hline Age (years) & $(\min .65, \max .82)$ & & \\
\hline
\end{tabular}


Table 2. Comparison of demographic characteristics and health literacy scale mean scores

\begin{tabular}{|c|c|c|c|c|}
\hline Variables & & n & Mean \pm SD & Statistic \\
\hline Gender & $\begin{array}{l}\text { Male } \\
\text { Female }\end{array}$ & $\begin{array}{l}376 \\
607\end{array}$ & $\begin{array}{l}44.047 \pm 9.44 \\
44.476 \pm 8.89\end{array}$ & $\begin{array}{l}U=113607.00 \\
p=0.906\end{array}$ \\
\hline Marital Status & $\begin{array}{l}\text { Married } \\
\text { Single }\end{array}$ & $\begin{array}{l}518 \\
465\end{array}$ & $\begin{array}{l}42.602 \pm 9.31 \\
46.217 \pm 8.46\end{array}$ & $\begin{array}{l}U=93692.50 \\
\mathbf{p}=\mathbf{0 . 0 0 0}\end{array}$ \\
\hline Educational Status & $\begin{array}{l}\text { Primary school } \\
\text { Secondary school } \\
\text { High school } \\
\text { University graduate } \\
\text { Yes }\end{array}$ & $\begin{array}{l}631 \\
224 \\
120 \\
8 \\
804\end{array}$ & $\begin{array}{l}44.600 \pm 9.676 \\
43.116 \pm 8.252 \\
44.625 \pm 7.130 \\
50.375 \pm 8.087 \\
44.782 \pm 8.752\end{array}$ & $\begin{array}{l}\mathrm{KW}=10.334 \\
\mathbf{p}=\mathbf{0 . 0 1 6} \\
\mathrm{U}=61498.00\end{array}$ \\
\hline Social Security & No & 179 & $42.201 \pm 10.296$ & $\mathrm{p}=\mathbf{0 . 0 0 2}$ \\
\hline Levels of income & $\begin{array}{l}\text { Less income than expenditure Equal } \\
\text { income and expenditure } \\
\text { More income than expenditure }\end{array}$ & $\begin{array}{l}431 \\
463 \\
89\end{array}$ & $\begin{array}{l}44.937 \pm 9.407 \\
43.933 \pm 9.062 \\
43.258 \pm 7.559\end{array}$ & $\begin{array}{l}\mathrm{KW}=3.282 \\
\mathrm{p}=0.194\end{array}$ \\
\hline $\begin{array}{l}\text { Chronic Disease } \\
\text { Status }\end{array}$ & $\begin{array}{l}\text { Yes } \\
\text { No }\end{array}$ & $\begin{array}{l}891 \\
92\end{array}$ & $\begin{array}{l}44.791 \pm 8.805 \\
39.673 \pm 10.569\end{array}$ & $\begin{array}{l}U=29708,00 \\
\mathbf{p}=\mathbf{0 . 0 0 0}\end{array}$ \\
\hline $\begin{array}{l}\text { Type of Chronic } \\
\text { Disease }\end{array}$ & $\begin{array}{l}\text { Diabetes } \\
\text { Hypertension } \\
\text { Cholesterol } \\
\text { Osteoporosis } \\
\text { Other }\end{array}$ & $\begin{array}{l}203 \\
277 \\
120 \\
138 \\
153\end{array}$ & $\begin{array}{l}45.064 \pm 8.273 \\
45.909 \pm 7.860 \\
44.300 \pm 10.489 \\
43.898 \pm 8.312 \\
43.594 \pm 9.885\end{array}$ & $\begin{array}{l}K W=9.674 \\
\mathbf{p}=\mathbf{0 . 0 4 6}\end{array}$ \\
\hline $\begin{array}{l}\text { Chronic Disease } \\
\text { Status in Family }\end{array}$ & $\begin{array}{l}\text { Yes } \\
\text { No }\end{array}$ & $\begin{array}{l}799 \\
184\end{array}$ & $\begin{array}{l}44.533 \pm 8.420 \\
43.353 \pm 11.587\end{array}$ & $\begin{array}{l}U=71778.00 \\
p=0.618\end{array}$ \\
\hline $\begin{array}{l}\text { Regular Drug Use } \\
\text { Status }\end{array}$ & $\begin{array}{l}\text { Yes } \\
\text { No }\end{array}$ & $\begin{array}{l}878 \\
105\end{array}$ & $\begin{array}{l}44.797 \pm 8.745 \\
40.257 \pm 10.901\end{array}$ & $\begin{array}{l}U=36235.00 \\
\mathbf{p}=\mathbf{0 . 0 0 0}\end{array}$ \\
\hline
\end{tabular}

Table 3. Health literacy scale sub-dimension mean scores and total scale mean score

\begin{tabular}{lcc} 
& Mean \pm SD & Min- Max \\
\hline Functional Health Literacy Sub-Dimensions & $15.616 \pm 4.72$ & $5.00-25.00$ \\
Interactive Health Literacy Sub-Dimension & $15.866 \pm 3.70$ & $5.00-25.00$ \\
Critical Health Literacy Sub-Dimension & $12.829 \pm 3.11$ & $4.00-20.00$ \\
Health Literacy Scale Mean Total Score & $44.00 \pm 9.10$ & $14.00-68.00$
\end{tabular}

Table 4. The correlation between health literacy scale mean total score and age

\begin{tabular}{ll}
\hline & Age (Years) \\
\hline Health Literacy Scale Mean Total Score & r p \\
\hline
\end{tabular}

\section{Discussion}

The findings of this study carried out to determine the health literacy of elderly individuals are discussed in the following section.

The mean HLS score of the participants was 44.00 \pm 9.10 . The mean HLS score of the elderly individuals obtained in this study was moderate, and it was lower than the mean scores obtained in studies on adults. In other studies that used different measurement tools on elderly individuals, the health literacy levels were found to be moderate and significantly lower than those of adults $(1,13)$. In the studies conducted by
Ugurlu and by Cimen and Temel in Turkey, the health literacy level of elderly individuals was found to be close to moderate $(14,15)$. It is considered that the effects of the natural ageing process, differences in interest level, interaction with environmental stimuli, dependence on others, insufficient perception, attention deficit and functional decline have an effect in the low scores of health literacy of the participants in the older age group $(1,16)$. In addition, it is considered that the decrease in the level of education in Turkey may be a factor affecting the decrease in the health literacy levels of the elderly compared with 
those of adults (17). In fact, in the systematic review of Paasche-Orlow and Wolf, it was reported that low health literacy level is related to education level (18). When the studies conducted in Turkey are examined, it can be seen that low education level, literacyrelated activities and mean health literacy scores affect each other $(14,15)$.

Health literacy is examined in three important dimensions: functional, interactive (communicative) and critical (19). Functional health literacy is based on basic reading and writing ability, and people at this level can read health education materials. The mean functional health literacy sub-dimension score of elderly participants was $15.616 \pm 4.72$. Similar results have been obtained in the studies conducted $(19,20)$. Interactive health literacy means that people have social and cognitive skills in communicating with health providers. Individuals at this level can benefit from different health activities and can easily use their knowledge in changing health conditions (19). In our study, the mean interactive health literacy subdimension score was $15.866 \pm 3.70$. Similar results were obtained in studies conducted in other countries $(19,20)$. Critical health literacy requires improved cognitive, social skills and critical thinking capability. Thus, individuals can critically evaluate health information; improve their capacities and understand and interpret the social, political and economic dimensions of health (20). The mean critical health literacy sub-dimension score was $12.829 \pm 3.11$ in our study. Similar to our study, the mean critical health literacy score was found to be lower than that of other sub-dimensions in other studies $(9,19-21)$. This situation is considered to be owing to the decrease in the cognitive and social abilities of the individuals as they age, and insufficient internalisation of the information received. In addition, owing to the respect for elderly people in Turkish culture, all the needs of the elderly regarding healthcare are provided by family members (usually, by their children). As a result, the elderly leaves all decisions regarding their health to their family members; retain the information they receive at a lexical level and do not test its reliability and cannot interpret the social, political and economic dimensions of health $(14,15)$.

There was a statistically significant difference between the mean HLS score of the elderly and marital status $(p<0.05)$. Single participants had a higher mean score than married individuals. When we look at the literature, although some studies did not reveal any difference, other studies reported that the mean scores of married individuals were higher than those of single individuals $(6,14,15,22)$. In our study, it was determined that the mean score of singles was higher. This difference was attributed to the region where the study was conducted and the fact that divorced or widowed individuals were evaluated in a single category.

There was a statistically significant difference between the mean HLS score of the elderly and social security status $(p<0.05)$. Individuals with social security had a higher mean score than those who did not. Similarly, a significant difference was also found in the study conducted by Cimen and Temel (15).

There was a statistically significant difference between the mean HLS score of the elderly and chronic disease status $(\mathrm{p}<0.05)$. Similar results were obtained in the study by Ugurlu (14). Conversely, Cimen and Temel found no significant difference between the number of chronic diseases and mean score of health literacy (15). This difference between the studies is considered to be caused by the different regions in which the studies are conducted. Furthermore, this situation is considered to be owing to the necessity of individuals with chronic diseases receiving more health services and paying attention to their treatment.

Based on the type of chronic disease, the difference between the HLS mean scores of elderly individuals was statistically significant $(\mathrm{p}<0.05)$. In the post hoc (Dunn) analysis, the difference was found to be caused by osteoporosis and hypertension. The HLS score mean of individuals with hypertension was found to be higher. This result suggests that the daily follow-up of individuals with hypertension is relatively higher than those with osteoporosis and that the elderly people's health literacy levels have increased due to blood pressure monitoring. In a study conducted in China, the HLS score mean of individuals who had blood pressure control was found to be higher (23).

There was a statistically significant difference between the mean HLS score of the elderly and regular drug use $(p<0.05)$. The health literacy levels of drug users were higher. Similarly, a significant difference was found in other studies $(13,14)$. It is considered that this may be due to the fact that individuals who regularly use drugs have more knowledge about how, when and how the drug should be used, and their awareness levels are higher.

There was a weak negative correlation between the HLS mean score of the elderly and age ( $\mathrm{r}=$ $-0.096)(\mathrm{p}<0.05)$. While age increased, the mean health literacy scores of elderly individuals decreased. According to the studies conducted, it was found that individuals aged over 65 years were lower compared with those of individuals in other age 
groups (14,24-26). It can be said that ageing is one of the major elements affecting health literacy. The low health literacy among the elderly affects the individual and the country negatively in many ways. Baker et al. determined that inadequate health literacy skills were independently associated with an increased mortality risk among the elderly in a community (13). In a systematic review, the effects of low health literacy on health were evaluated, and it was found to be associated with more hospitalizations, more use of emergency services, receiving less protective health care, inability to use medicines properly, poor understanding of healthrelated messages and particularly poor health and higher mortality in the elderly (1). Therefore, health literacy has become an important matter in Turkey, which has an increasing elderly population.

\section{Limitations of the Study}

This study was limited to individuals aged over 65 years admitted to Family Health Centres affiliated to the Provincial Health Directorate.

\section{Conclusion}

As a result of our research, the health literacy of elderly individuals was found to be at a moderate level, and this needs to be further improved. Today, owing to the change in the provision of health services, the responsibilities of the elderly towards their own health have increased. Since the incidence of chronic diseases is high, elderly people are expected to be more active in taking responsibility for their treatment and care. In this respect, it is important to increase the health literacy level of elderly people. To increase the health literacy level of elderly people, local governments, health institutions and health workers should take the necessary measures. It is recommended that health personnel, especially public health nurses, use special methods, a simpler language and materials in health education programmes and receive feedback from elderly individuals.
Ethics Committee Approval: Ethics committee approval (Dated 04/11/2018 and Number 32) and institutional approval from Provincial Health Directorate were obtained for this study. Volunteerism was taken into consideration in the determination of participants, and other ethical principles were also followed.

Peer-review: Externally peer-reviewed.

\section{Author Contributions:}

Concept: H.Y.B, Design: H.Y.B, M.Y, Literature Search: H.Y.B, M.Y, Data Collection and Processing: H.Y.B., M.Y.; Analysis or Interpretation: H.Y.B., M.Y. Writing: H.Y.B., M.Y. Conflict of Interest: No conflict of interest was declared by the authors.

Financial Disclosure: The authors declared that this study hasn't received no financial support.

\section{References}

1. Berkman ND, Sheridan SL, Donahue KE, Halpern DJ, Crotty K. Low health literacy and health outcomes: an updated systematic review. Ann Intern Med. 2011; 155(2): 97-107.

2. Geboers B, Winter AF, Spoorenberg SL, Wynia K, Reijneveld SA. The association between health literacy and self-management abilities in adults aged 75 and older, and its moderators. Qual Life Res. 2016; 25(11): 2869-77.

3. World Health Organization. Achieving health equity: From root causes to fair outcomes, 2007 (cited 2019 December 10). Available from: URL: https://www.who.int/social_determinants.pdf.

4. World Health Organization. Social determinants of health in countries in conflict a perspective from the Eastern Mediterranean Region. 2008 (cited 2019 December 10). Available from: URL: http://www.emro.who.int/dsaf/dsa955.pdf.

5. World Health Organization. Promoting health and development: closing the implementation gap. [cited 19 April 2019]. Available from: URL: https://www.who.int/mediacentre/events/meetings/7 gchp/en/.

6. Bozkurt H, Demirci H. Health literacy among older persons in Turkey. Aging Male. 2019; 22(4): 272-7.

7. Lee HY, Rhee TG, Kim NK, Ahluwalia JS. Health literacy as a social determinant of health in Asian American immigrants: findings from a population-based survey in California. J Gen Intern Med. 2015; 30(8): 1118-24. 
8. Von Wagner C, Knight K, Steptoe A, Wardle J. Functional health literacy and health-promoting behaviour in a national sample of British adults. $\mathrm{J}$ Epidemiol Community Health. 2007; 61(12): 108690.

9. Zanchetta MS, Perreault M, Kaszap M, Viens C. Patterns in information strategies used by older men to understand and deal with prostate cancer: An application of the modelisation qualitative research design. Int J Nurs Stud. 2007; 44(6): 961-72.

10. Baker DW, Gazmararian JA, Williams MV, Scott T, Parker RM, Green D, et al. Health literacy and use of outpatient physician services by Medicare managed care enrollees. J Gen Intern Med. 2004; 19(3): 215-20.

11. Suka M, Odajima T, Kasai M, Igarashi A, Ishikawa $\mathrm{H}$, Kusama $\mathrm{M}$, et al. The 14-item health literacy scale for Japanese adults (HLS-14). Environ Health Prev Med. 2013; 18(5): 407-15.

12. Turkoglu N, Kilic D. In reliability and validity study of the Turkish form of health literacy scale. 18. ISPOG Congress; May 12-14; Malaga-Spain: 2016.

13. Baker DW, Wolf MS, Feinglass J, Thompson JA. Health literacy, cognitive abilities, and mortality among elderly persons. J Gen Intern Med. 2008; 23(6): 723-6.

14. Ugurlu Z. Evaluation of the health literacy of the patients applying to health institutions and the suitability of the educational materials used for health literacy. Ankara: Baskent University Institute of Health Sciences. 2011.

15. Cimen Z, Temel AB. Investigation Of Health Literacy, Perception Of Health And Related Factors In Elderly Patients With Chronic Illness. Ege University Faculty of Health Sciences Journal. 2017; 33(3): 105-27.

16. Sørensen K, Van den Broucke S, Fullam J, Doyle G, Pelikan J, Slonska Z, et al. Health literacy and public health: a systematic review and integration of definitions and models. BMC Public Health. 2012; 12(1): 1-3.

17. 17. Hacettepe University Institute of Population Studies. Turkey Demographic and Health Survey 2013. (cited 2019 December 10). Available from: URL:

http://www.hips.hacettepe.edu.tr/tnsa2013/rapor/TN SA_2013_ana_rapor.pdf.

18. Paasche-Orlow MK, Wolf MS. The causal pathways linking health literacy to health outcomes. Am J Health Behav. 2007; 31(1): 19-26.

19. Nutbeam D. The evolving concept of health literacy. Soc Sci Med. 2008; 67(12): 2072-8.
20. Sykes S, Wills J, Rowlands G, Popple K. Understanding critical health literacy: a concept analysis. BMC Public Health. 2013; 13(1): 150.

21. Inoue $\mathbf{M}$, Takahashi $M$, Kai I. Impact of communicative and critical health literacy on understanding of diabetes care and self-efficacy in diabetes management: a cross-sectional study of primary care in Japan. BMC Fam Pract. 2013; 14(1): $1-9$.

22. Tang YH, Pang SM, Chan MF, Yeung GS, Yeung VT. Health literacy, complication awareness, and diabetic control in patients with type 2 diabetes mellitus. J Adv Nurs. 2008; 62(1): 74-83.

23. Shi D, Li J, Wang Y, Wang S, Liu K, Shi R, et al. Association between health literacy and hypertension management in a Chinese community: a retrospective cohort study. Intern Emerg Med. 2017; 12(6): 765-76.

24. Kobayashi LC, Wardle J, Wolf MS, von Wagner C. Cognitive function and health literacy decline in a cohort of aging English adults. J Gen Intern Med. 2015; 30(7): 958-64.

25. Morris NS, MacLean CD, Littenberg B. Change in health literacy over 2 years in older adults with diabetes. Diabetes Educ. 2013; 39(5): 638-46.

26. U.S. Department of Health and Human Services. Health, United States, with chartbook on trends in the health of Americans. (cited 2019 December 10). Available from: URL:

http://www.cdc.gov/nchs/data/hus/hus07.pdf. 